\title{
Muscle mass assessment in renal disease: the role of imaging techniques
}

\author{
Alice Sabatino ${ }^{1}$, Claudia D'Alessandro ${ }^{2}$, Giuseppe Regolisti ${ }^{1,3}$, Francesca di Mario ${ }^{1,3}$, Giuseppe Guglielmi ${ }^{4}$, \\ Alberto Bazzocchi ${ }^{5}$, Enrico Fiaccadori ${ }^{1,3}$
}

${ }^{1}$ Dipartimento di Medicina e Chirurgia, Università di Parma, Parma, Italy; ${ }^{2}$ Department of Clinical and Experimental Medicine, University of Pisa, Pisa, Italy; ${ }^{3}$ UO Nefrologia, Azienda Ospedaliero-Universitaria di Parma, Parma, Italy; ${ }^{4}$ Department of Clinical and Experimental Medicine, University of Foggia, Foggia, Italy; ${ }^{5}$ Diagnostic and Interventional Radiology, IRCCS Istituto Ortopedico Rizzoli, Bologna, Italy

Correspondence to: Dott.ssa Alice Sabatino. Dipartimento di Medicina e Chirurgia, Università degli Studi di Parma, Via Antonio Gramsci 14, Parma 43126, Italy. Email: alice.sabatino86@gmail.com.

\begin{abstract}
Muscle wasting is a frequent finding in patients with chronic kidney disease (CKD), especially in those with end-stage kidney disease (ESKD) on chronic dialysis. Muscle wasting in CKD is a main feature of malnutrition, and results principally from a vast array of metabolic derangements typical of the syndrome, that converge in determining reduced protein synthesis and accelerated protein catabolism. In this clinical setting, muscle wasting is also frequently associated with disability, frailty, infections, depression, worsened quality of life and increased mortality. On these grounds, the evaluation of nutritional status is crucial for an adequate management of renal patients, and consists of a comprehensive assessment allowing for the identification of malnourished patients and patients at nutritional risk. It is based essentially on the assessment of the extent and trend of body weight loss, as well as of spontaneous dietary intake. Another key component of this evaluation is the determination of body composition, which, depending on the selected method among several ones available, can identify accurately patients with decreased muscle mass. The choice will depend on the availability and ease of application of a specific technique in clinical practice based on local experience, staff resources and good repeatability over time. Surrogate methods, such as anthropometry and bioimpedance analysis (BIA), represent the most readily available techniques. Other methods based on imaging modalities [dual-energy X-ray absorptiometry (DXA), magnetic resonance imaging (MRI), and whole body computed tomography (CT)] are considered to be the "gold standard" reference methods for muscle mass evaluation, but their use is mainly confined to research purposes. New imaging modalities, such as segmental CT scan and muscle ultrasound have been proposed in recent years. Particularly, ultrasound is a promising technique in this field, as it is commonly available for bedside evaluation of renal patients in nephrology wards. However, more data are needed before a routine use of ultrasound for muscle mass evaluation can be recommended in clinical practice.
\end{abstract}

Keywords: Body composition; chronic kidney disease (CKD); end-stage kidney disease (ESKD); muscle loss; ultrasound

Submitted Nov 15, 2019. Accepted for publication Feb 12, 2020.

doi: 10.21037/qims.2020.03.05

View this article at: http://dx.doi.org/10.21037/qims.2020.03.05

\section{Introduction}

Chronic kidney disease (CKD) is a global health issue, since $11-13 \%$ of the world population can be diagnosed with CKD in different severity stages (1). The syndrome is characterized by several nutritional and metabolic derangements, that become clinically evident in most advanced stages. A number of metabolic conditions commonly observed in severe CKD (e.g., acidosis, 
Table 1 Methods frequently used for the assessment of muscle mass in renal disease in research and in clinical practice

\begin{tabular}{ll}
\hline Research & Clinical practice \\
\hline Bioimpedance analysis (BIA) (surrogate method) & Anthropometry (surrogate method) \\
Dual energy X-ray absorptiometry (DXA) & BIA (surrogate method) \\
Computed tomography (CT) & Lumbar (L3) muscle cross-sectional area by CT \\
Magnetic resonance imaging (MRI) & DXA \\
Ultrasound & Ultrasound (?) \\
\hline
\end{tabular}

inflammation, oxidative stress, and impaired insulin/ insulin-like growth factor axis function etc.), chronic comorbidities, and renal replacement therapy (RRT) (e.g., dialysis) per se have a negative impact on nutritional status, as they can induce muscle wasting through the alteration of the balance between muscle protein anabolism and catabolism (2).

The evaluation of nutritional status is usually based on a comprehensive assessment including patient history, physical examination, evaluation of nutrient intake, biochemical markers and screening methodologies that provide a global picture of patients' protein and energetic reserve, as well as their nutritional risk (3). An important part of this evaluation is the assessment of body composition, which refers typically to the quantification of adipose tissue and, more importantly, of muscle mass, aiming for an early diagnosis and monitoring in patients at risk of muscle loss.

Nowadays, several methodologies are available for the estimation/measurement of muscle mass (Table 1). Some of these techniques, such as anthropometry, bioimpedance analysis (BIA) and, with some limitations, dual energy X-ray absorptiometry (DXA) are available for routine patient assessment (4). Other methodologies-mainly imaging techniques, such as computed tomography (CT) and magnetic resonance imaging (MRI) - are currently used only in research studies and represent the gold standard (5). More recently, muscle ultrasound (US) has been studied as an alternative tool for the assessment of muscle mass at the bedside in different clinical settings, including CKD and acute kidney injury (AKI) (6-14). While anthropometry and BIA are surrogates of muscle mass, imaging techniques should be preferred for a precise quantification of both adipose and muscle tissues.

In this paper, we provide an overview of the different methods currently available for the assessment of body composition in renal disease, focusing on imaging techniques and their applicability for the diagnosis of muscle wasting.

\section{Impact of muscle wasting in renal disease}

Skeletal muscle is vital to mobility, posture, strength and balance as it allows the performance of physical activities of daily living (15). In addition, it is also a pivotal metabolic and homeostatic organ, via crosstalk with other organs systems (16). Most importantly, it plays a key role in protein metabolism as a source of amino acids when protein intake is insufficient, thus preserving the protein content of other essential organs $(16,17)$. However, when muscles undergo chronic catabolism to supply amino acids for other metabolic purposes, a reduction in lean body mass (LBM) is observed. This has potentially serious clinical consequences such as muscle weakness, impaired physical function, increased morbidity and mortality (18). In fact, as low as $10 \%$ loss of LBM is associated with increased risk of death, due to impaired immune response and increased susceptibility to infections, while a $40 \%$ reduction is incompatible with life (19).

Decreased muscle mass is a frequent finding in patients with end-stage kidney disease (ESKD) on hemodialysis (7), with muscle loss occurring earlier and more severely in this population in comparison to age-matched controls $(20,21)$. This phenomenon has been associated to nutritional problems, chronic diseases, a sedentary lifestyle and drugrelated side effects $(22,23)$, and its prevalence seems to be strongly related to the worsening of kidney function (24). The consequences of muscle loss are not only physically debilitating. In fact, many studies in the past decades have also linked muscle wasting in ESKD patients on dialysis with worse quality of life, depression, protein energy malnutrition, cardiovascular complications, as well as 


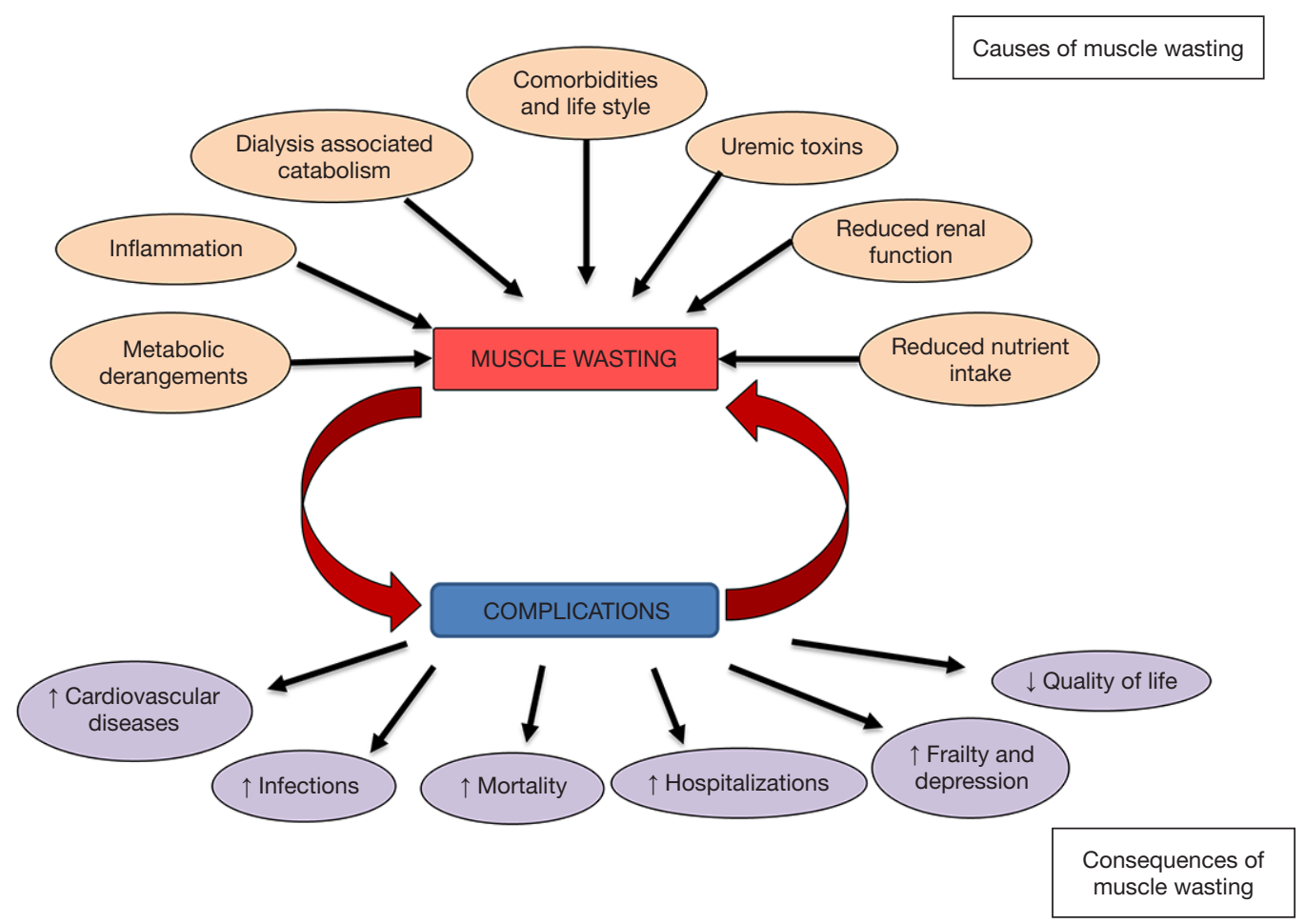

Figure 1 Pathophysiology of muscle wasting in chronic kidney disease.

with increased hospitalization and mortality (25-29). In addition, the negative consequences of muscle wasting are not only a concern to patients on dialysis, as also in kidney transplant recipients sarcopenia, which is characterized by a loss of muscle mass and function, correlates with increased mortality, graft failure, and more frequent postoperative complications (30-33).

There is strong evidence linking muscle wasting to worse prognosis in CKD and other non-communicable diseases states, such as chronic obstructive pulmonary disease (COPD), or chronic heart failure (CHF) (34-38). Despite the diverse pathophysiology of these diseases, all are associated with increased protein catabolism through the upregulation of the ubiquitin-proteasome system (UPS) (35,39-42).

Most of these pathological conditions are associated with various degrees of chronic inflammation, which plays a critical role in the onset of muscle atrophy and malnutrition. During the physiologic process of atrophy, the degradation of myofibrillar and soluble proteins is accelerated. However, in systemic wasting conditions, protein synthesis also decreases, leading to a negative balance between degradation and synthesis, which will eventually result in muscle loss, reduced body weight, weakness and disability (43).
Physical disability is characterized by difficulties in performing activities of daily living, worsens quality of life and increases the risk of death (44).

\section{Pathophysiology of muscle wasting in CKD}

The pathogenesis of muscle wasting in CKD is multifactorial and is characterized by a persistent vicious cycle between muscle wasting and its complications (Figure 1). Based on currently available evidence, the causes of muscle wasting in CKD can be classified into two groups: (I) causes related to kidney disease per se; and (II) causes related to chronic low-grade inflammation, typical of patients on dialysis but also present in earlier stages of CKD $(45,46)$. Factors related to kidney disease that contribute to the loss of skeletal muscle mass (SMM) include inadequate spontaneous nutrient intake, metabolic acidosis, vitamin D deficiency, insulin resistance, low physical activity, proteinuria and hyperparathyroidism (2).

Inadequate nutrient intake is quite frequent in these patients, and is the most important factor that contributes to the development of muscle wasting. Progressive loss of appetite (anorexia) begins already in early stages of 
CKD (47), and worsens in parallel to the loss of kidney function. In this clinical setting, anorexia is a frequent consequence of taste abnormalities, accumulation of uremic toxins, dysregulation of gastrointestinal homeostatic mechanisms, altered blood concentration of appetite regulators and deranged hypothalamic output (47). In addition, CKD patients on unsupervised dietary nutritional treatment (the so called low-protein diets) usually undergo prolonged restrictions of protein intake, as well as of phosphorus, potassium and sodium, that can be deleterious if accompanied by inadequate energy intake $(48,49)$. Furthermore, frailty, poverty, advanced age and multiple acute or chronic comorbidities may also contribute to suboptimal nutrient intake in ESKD (30,50-52).

Metabolic acidosis is a very frequent complication of ESKD, is associated with increased mortality (53), and plays an important role in the stimulation of protein catabolism (54). In fact, metabolic acidosis increases intracellular protein degradation by activating both the caspase- 3 and the UPSs, promotes the oxidation of branched chain amino acids, reduces protein synthesis and favors insulin and GH resistance, thus leading to negative protein balance $(55,56)$. These effects can be reversed by bicarbonate administration $(57,58)$.

Insulin resistance is one of the most important metabolic challenges in diabetic patients with CKD, who suffer from more severe protein degradation and loss of LBM in comparison to non-diabetic patients $(59,60)$. However, insulin resistance can be observed also in non-diabetic patients on dialysis, and is associated with increased protein catabolism mediated primarily by the ubiquitin-proteasome pathway, with insulin resistance acting through a decrease in muscle phosphatidylinositol 3 kinase (PI3K) (61). In addition to metabolic acidosis, vitamin $\mathrm{D}$ deficiency also contributes to the development of insulin resistance by affecting pancreatic insulin secretion $(62,63)$. Moreover, vitamin D deficiency can directly affect muscle synthesis (64).

Among other causes for the development of muscle wasting, chronic inflammation is a frequent finding in ESKD patients. It may contribute to both an increase in nutritional needs and to anorexia, through an imbalance between the orexigenic/anorexigenic mechanisms that control the energetic homeostasis of renal patients $(51,52)$. Several factors are thought to contribute to the pathogenesis of inflammation in ESKD: worsening of renal function, which reduces the elimination of pro-inflammatory cytokines and uremic toxins; the presence of comorbidities; and factors related to the dialytic treatment per se, such as membrane and dialysis fluid bioincompatibility (65).
Furthermore, the available evidence suggests a pivotal role of the gastrointestinal tract in the pathogenesis of chronic inflammation in CKD, as a consequence of intestinal dysbiosis and barrier disruption (66-68). In healthy subjects, beneficial bacterial species characterized by a predominant saccharolytic metabolism outweigh pathobionts. They are responsible for fermenting complex carbohydrates and producing short chain fatty acids, such as acetate, butyrate and propionate, that serve as fuels for the intestinal epithelium and have also favorable immunomodulatory effects $(68,69)$. The uremic milieu and the reduced availability of non-digested complex carbohydrates, with the latter being a common consequence of the reduced intake of fibers characteristic of CKD/ESKD patients, are responsible for negative effects both on the resident microbial population (i.e., dysbiosis,) and on the structure/function of the gastrointestinal tract, enhancing the permeability of the intestinal barrier $(66,68,70)$. This dysbiotic environment is characterized by a switch towards a more proteolytic metabolic profile, leading to an increase in protein fermentation (putrefaction) and the ensuing generation of increased amounts of potentially toxic compounds (i.e., ammonium, thiols, phenols, indoles) that are absorbed into the bloodstream $(68,70)$. In addition, increased urea influx from the blood into the gut promotes urea hydrolysis by microbial species that contain urease to form large quantities of ammonia, which is converted to ammonium hydroxide (71). Ammonia and ammonium hydroxide are toxic compounds known to disrupt the integrity of the gut epithelial barrier, also increasing its permeability (68). The deranged and more permeable intestinal barrier may facilitate bacterial translocation, i.e., the passage of bacteria or their structural component lipopolysaccharide (LPS) from the gut lumen to the blood $(68,70)$, triggering the inflammatory cascade. Tumor necrosis factor alpha (TNFa), interleukin 6 (IL-6), IL-8, and interferon gamma (IFN- $\gamma$ ) are in fact mentioned among the most frequently observed indicators and stimulators of muscle proteolysis, while C-reactive protein (CRP) seems to be a useful and inexpensive, although nonspecific, marker of systemic inflammation $(25,72)$.

Finally, physical activity is markedly reduced in hemodialysis patients in comparison to age-matched controls $(73,74)$. Reasons for reduced physical activity are fatigue on dialysis days, lack of time and motivation, physical problems and pain $(75,76)$. In this clinical setting, physical inactivity represents a modifiable risk factor for the development of muscle loss and, in addition to 
the promotion of muscle atrophy, it may cause a further increase in the already high level of cardiovascular risk in these patients $(74,77)$. Physical exercise, even in dialyzed patients, ameliorates depression and improves quality of life, appetite and energy supply (77).

\section{Methods to assess body composition}

\section{Anthropometry}

Anthropometry can be considered the first step in the evaluation of the nutritional status of CKD patients. It includes the measurement of body dimensions, i.e., body weight, height, skinfold thickness and circumferences of limbs, waist and hips. From these measures, it is possible to calculate further parameters such as the body mass index (BMI) (weight/height ${ }^{2}, \mathrm{~kg} / \mathrm{m}^{2}$ ), waist/hip ratio, and surface area.

Due to low reproducibility and reliability on an individual basis, anthropometric measurements are sometimes considered to be less important than other measurements requiring more sophisticated techniques (78). However, they are simple to perform, noninvasive, cheap, provide immediate results and are applicable on a large scale. Thus, the use of specific tools and the standardization of procedures is mandatory to achieve reliable measurements and to ensure their comparability and reproducibility over time, especially in CKD patients in whom body composition can be influenced by various factors related to the disease itself and in particular the hydration state.

Mid-arm circumference (MAC) measurement can be easily applied where other instruments are not available or usable, for example in bedridden patients. MAC is considered a better prognostic indicator of the risk of death associated with malnutrition than the weight-to-height ratio (4). Higher values of MAC and calf circumference (CC) are indicative of greater lean mass and have also been associated with reduced mortality in hemodialysis patients $(4,79)$. Tricipital skin fold (TSF) thickness is the most used single-site skinfold measurement, as it is easily measurable and reference data are available for comparison. There are several equations to derive fat mass from skin fold measurements at different sites, but no equation exists for a single-site skinfold measurement (80-82). Hemodialysis patients with higher BMI and body fat mass seem to have better quality of life and survival (83).

TSF and MAC are used to calculate the middle-arm muscle circumference (MAMC) and the middle-arm muscular area (MAMA) using specific formulas:

MAMC $=$ MAC $-($ TSF $\times \pi)$

$\mathrm{MAMA}=[\mathrm{MAC}-(\pi \times \mathrm{TSF})] 2 / 4 \pi$

Higher MAMC has been found to be predictive of a lower death risk in patients on maintenance dialysis (84). MAMC has been validated versus LBM measured by DXA, a gold standard method for body composition assessment, and a strong correlation has been demonstrated in patients on maintenance hemodialysis, suggesting that MAMC can be considered a valid surrogate of muscle mass (29). MAMC may also reflect adequacy of energy and protein intake, and its reduction can be considered an index of sarcopenia and a sign of malnutrition or wasting (85). The integrated evaluation of MAMC and TSF measurements (MAMC low/ high + TSF low/high) may help in the estimation of survival in hemodialysis patients; in this respect, it has been shown that patients with high MAMC combined with either high or low TSF compared to low MAMC and low TSF have the greatest survival probability (29). However, despite its usefulness in clinical practice, because of its intrinsic limitations anthropometry should be complemented by other methods to obtain more accurate results in assessing body composition.

\section{BIA}

BIA estimates body composition based on the resistance of the body to the passage of an alternating electrical current. Different techniques are available depending on current frequency and/or the site of measurement. On the basis of the current frequencies, two approaches have been developed. In single-frequency bioimpedance analysis (SF-BIA) a low frequency of $50 \mathrm{~Hz}$ is delivered, whereas in multifrequency bioimpedance analysis (MF-BIA) the instrument delivers different frequencies that generally vary from 5 to $1,000 \mathrm{kHz}$ or a broadband of frequencies [in this case the technique is called bioimpedance spectroscopy (BIS)]. Based on sites where measurements are performed, BIA is classified as whole body or segmental.

Impedance $(Z)$ represents the force that interferes with the flow of electric current, and is the result of the vectorial sum of the resistance $(\mathrm{Rz})$ and the reactance $(\mathrm{Xc})$. The resistance is the component of the impedance corresponding to the flow of current in fluids, while the reactance is the component of the impedance corresponding to the flow through cell membranes, which behave like capacitors due to their lipid bilayer structure. In the human body, electric 


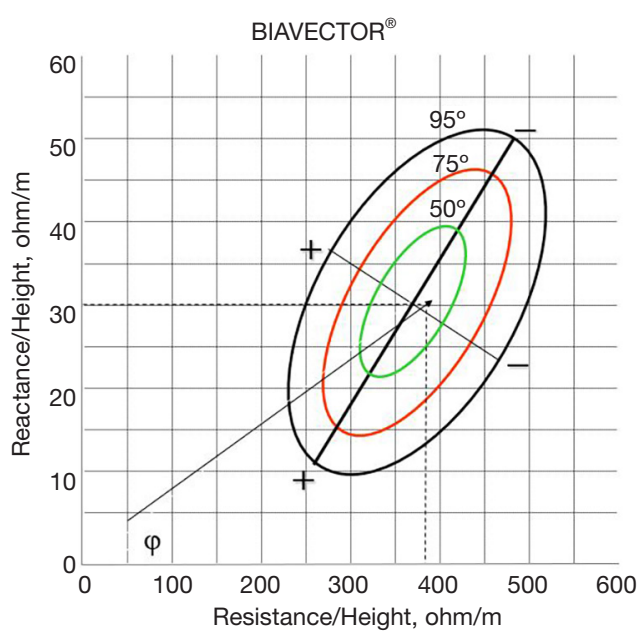

Figure 2 RXc graph derived from bioelectrical impedance analysis (BIA).

current is conducted by electrolytes present in body fluids, most of which are contained in the fat free mass (FFM). FFM includes bone tissue and body cell mass (BCM), that represents the metabolically active component and includes the SMM. Total body water (TBW), that represents $73 \%$ of FFM in normo-hydrated subjects, is the sum of intracellular water (ICW) and extracellular water (ECW).

The most investigated bioelectric index is the phase angle $(\mathrm{PA})$ that derives from a proportion between resistance and reactance according to the following formula:

$\mathrm{PA}=$ Arctang $(\mathrm{Xc} / \mathrm{Rz}) \times 180 \times \pi$

The PA is considered the BIA parameter that best predicts survival in CKD and ESKD patients on peritoneal dialysis and maintenance hemodialysis, as well as in patients with HIV, cancer and other diseases (86-93). A PA $\leq 4.5^{\circ}$ has been associated with a worse clinical outcome in patients undergoing hemodialysis (94).

As mentioned above, CKD is accompanied by fluid retention and derangements of water distribution between the intra- and the extracellular compartments. In this clinical setting BIA should be considered, as it can detect changes in body fluids, is noninvasive and easy to perform at the bedside $(95,96)$. Using research data obtained in population samples of adequate dimension, nomograms have been developed based only on bioelectric measurements, such as the RXc Graph, that are useful for identifying conditions of adequate or altered hydration state. This nomogram allows a qualitative diagnosis from the resistance and reactance values directly measured by the instrument, using SF-BIA at $50 \mathrm{KHz}$ frequency. Resistance and reactance, normalized for height $(\mathrm{H})$, the length of the conductor (the patient's body), are plotted on the RXc Graph with three elliptical probability regions: 50\%, 75\%, 95\% tolerance ellipses (Figure 2). Rz/H and $\mathrm{Xc} / \mathrm{H}$ are the two components of the impedance vector. The length of the vector represents the size of the impedance. The movement of the vector along the major axis of the ellipses, gives clinical information on the hydration state and is not influenced by body weight (97).

While SF-BIA is the first and the most used method to assess body compartments, in the last years, body composition monitors based on the application of multiple current frequencies (MF-BIA) have been preferred in clinical research because they estimate separately ICW and ECW (whereas SF-BIA gives information only on ECW), allowing a more precise measurement of body water content. At low frequencies, the current flows through the extracellular fluids, while at high frequencies it can pass through the cells. By changing the current frequency, MFBIA provides therefore information on the distribution of water outside and inside the cells.

Mathematical models and empirical formulae derived from a reference population are applied to estimate body characteristics. These formulas are derived from a population of healthy subjects belonging to specific ethnic groups; thus, their application in patients with possible alteration of the hydration state and from different ethnic groups could yield biased values. Some authors have shown that MF-BIA is preferable to SF-BIA in the assessment of muscle mass, as it is less affected by over-hydration (98). In hemodialysis patients, estimation of muscle mass and ECW with MF-BIA showed a good correlation with measurements performed with gold standard techniques such as isotopic methods $\left(\mathrm{D}_{2} \mathrm{O}\right.$ and $\left.\mathrm{K}^{40}\right)$ and MRI $(98,99)$.

While the hydration state of CKD/ESKD patients may represent an important source of bias in the assessment of muscle mass by BIA, some precautions can be applied to allow greater reliability and reproducibility of this method, both with single or multi-frequency BIA:

* If BIA is used to assess hydration state or to define dry weight, it is recommended that measurements be performed both before and after the dialysis treatment, in order to detect changes in $\mathrm{Rz}$ and $\mathrm{Xc}$ (the only two parameters really measured by the instruments, as all of the other parameters are estimated by equations);

* If BIA is used to assess muscle mass, it is important to perform the examination after a time interval of 15-120 minutes since the end of the dialysis session, 
that is in the dry-weight state, preferably after the second dialysis session of the week (100). In these conditions the mathematical equations provided with the BIA software may give a more reliable estimation of TBW and FFM;

* Regarding peritoneal dialysis patients, some investigators have reported that the presence of dialysis solutions in the peritoneal space has a negligible effect on the assessment of body composition, while others observed an overestimation of body water and cell mass $(101,102)$. Thus, for a more accurate assessment of body composition in peritoneal dialysis patients, it is advisable to perform BIA when the abdomen is empty.

\section{Imaging methods}

\section{DXA}

DXA is considered a gold standard method for the assessment of body composition. It is a well-tolerated imaging technique that measures the body relative attenuation of two low-dose X-ray beams with different levels of energy, allowing the identification of different components of body weight, i.e., LBM, fat body mass (FBM) and bone. DXA measurements are based on a threecompartment model that includes total body mineral (from bones), LBM (or lean soft tissue), and fat tissue mass, as opposed to two-compartment models used in SF-BIA; it can also provide both segmental and whole body parameters of body composition.

The recent Sarcopenia, Cachexia and Wasting Disorders position paper recommends DXA as the reference method to assess muscle mass, in particular appendicular skeletal mass, and for the diagnosis of sarcopenia (80). Despite its current and frequent use in clinical practice for the assessment of osteoporosis and sarcopenia in the elderly (5), its accuracy may be affected by hydration state. In fact, DXA assumes that LBM has a constant hydration of $73 \%$, and fluctuations of the hydration state of patients with CKD/ESKD may overestimate or underestimate this parameter (103). Nonetheless, in CKD patients DXA measurements have been associated with physical functioning: measures of adiposity were in fact associated with lower functional ability, whereas higher muscle mass was associated with better physical function and quality of life in dialysis patients (27).

Notwithstanding it not being time-consuming and the minimal patient radiation exposure, evaluation by DXA is not feasible at the bedside, nor does it allow an accurate direct quantification of absolute compartmental tissue volumes. In addition, the cost of the machine and the need for trained radiology operators represent other limitations hampering its routine use for the assessment and monitoring of body composition.

\section{CT}

CT scan is a noninvasive test generally used for diagnostic and treatment purposes. It can be applied also for the assessment of body composition assessment as it provides high quality images that can differentiate and measure fat and lean body tissue. Moreover, it can distinguish between intra- and extra-abdominal fat, and can also detect the amount of infiltrated fat tissue in SMM, providing information regarding muscle quality. The procedure requires an $\mathrm{X}$-ray source that rotates around the patient emitting a beam of photons. The known differences in attenuations of X-rays between lean soft tissue and adipose tissue are used to separate them, as well as to determine the infiltration of fat in a particular lean soft tissue. Being a three-dimensional technique, CT can be used to perform direct volumetric measurements of organs. However, because CT uses ionizing radiation, CT-based body composition analysis is usually limited to two-dimensional images of one or a limited number of axial slices, allowing for the assessment of muscle area as a proxy to volume and minimizing the ionizing radiation dose. However, this approach limits the precision of the measurement, since the location of the slices may vary between scans.

In the renal population, $\mathrm{CT}$ has been applied to assess quadriceps muscle cross-sectional area (CSA) and volume $(104,105)$. In addition, CT has also been used to assess muscle density, which provides additional information regarding muscle quality or the degree of intramuscular fat infiltration (106). Recently, abdominal CT scan has been used in oncology and ICU to assess and monitor changes in muscle mass at the level of the third lumbar vertebra (L3), and may be a promising tool for patients undergoing abdominal CT for diagnostic reasons (107-109). In fact, the axial slice at the level of the third lumbar vertebra showed the highest correlation with total body skeletal muscle volume as assessed by MRI in healthy subjects (110). More recently, in cancer patients, muscle volume assessed by a CT scan at the third lumbar vertebra was highly correlated with FFM and appendicular SMM as assessed by DXA (111). In the CKD population, it has been used to validate surrogate 
methods for the assessment of muscle mass, such as BIA, anthropometry, subjective global assessment (SGA) and two predictive equations in non-dialysis CKD patients (112).

The European Consensus Statement for the diagnosis of sarcopenia $(44,108)$, recommends the use of CT as the gold-standard method for the assessment of muscle loss. In addition, because as it is not influenced by hydration status, it can be used in the CKD/ESKD population with better precision than DXA. However, given the radiation exposure and its high costs, the use of CT for body composition analysis is usually restricted to the research setting.

\section{MRI}

MRI is a noninvasive imaging technique that uses different properties of the nuclei of hydrogen present in water and fat to produce images of soft tissue in the body. By using quantitative fat water imaging, (or Dixon imaging), precise measurements of adipose and lean tissue, as well as the fat infiltration in organs, can be performed (113). It can give information about body structure and function for diagnostic and treatment purposes. Particularly, in the Dixon imaging, the different magnetic resonance frequencies of protons in fat and water are used to separate water and fat images, facilitating the differentiation of lean and adipose tissue compartments (114). Using this technique, a total body scan with sufficient spatial resolution can take only 6-8 minutes (115). As opposed to CT and DXA, MRI does not use ionizing radiation, which enables its use in a broad population without theoretically increasing the risk of cancer.

Recently published papers have suggested methods that automatically or semi-automatically identify skeletal muscle volumes using MRI (116-120). The fat referenced Dixon imaging protocol has been validated for its accuracy and precision in assessing muscle fat infiltration (121), while Thomas et al. reported test-retest reproducibility for whole body and compartmental muscle volumes with narrow limits of agreement (119).

In the ESKD population, MRI has been used to assess whether frailty and functional tests were associated with body composition (122). In particular, LBM was assessed by DXA, while MRI was used to assess the CSA of the thigh, and BIA was used to measure the PA. Low CSA of the quadriceps muscle and lower PA were associated with worse performance and functional status, while LBM estimated by DXA was not associated with performance and functional status (122). In a more recent study, the psoas muscle area measured at the level of L4-L5, i.e., the same level used for the measurement of abdominal fat content, provided a useful measure of whole-body muscle mass, showing a strong correlation with LBM by DXA $(r=0.74 ; \mathrm{P}<0.001)$, and with the quadriceps muscle CSA $(r=0.83 ; \mathrm{P}<0.001)$ in patients on hemodialysis (123). In addition, this study also validated the MRI-based assessment of the psoas muscle and quadriceps CSA as accurate predictors of sarcopenia (123).

MRI is considered more accurate than CT scans for the assessment of muscle mass because of the increased contrast between tissues with different molecular properties (124). However, just like CT, MRI is expensive and requires specialized personnel. In addition, cut-off values of muscularity are yet to be defined because sex, age, ethnicity and total body fat content are possible factors that influence muscle mass (125). Thus, despite its widespread availability in hospitals, MRI is currently only employed for diagnostic purposes, and its use for the assessment of nutritional status is limited to the research setting.

\section{Muscle US}

Recently, the application of US scan technique for the assessment of SMM in renal patients has aroused considerable interest. Its major advantages, compared to other modalities, are represented by low cost, portability, lack of radiation exposure and the possibility to be applied by non-specialized staff $(6,7,126)$. Portability is of particular interest in the CKD research setting and clinical practice, since patients can be evaluated during the hemodialysis session or outpatient visits. As no radiation is required, muscle US can be used in every kind of patient, including children and pregnant women. Another important advantage of US is that it allows real-time visualization of the target structure and, through echogenicity, it can provide information about the presence of inflammation, fibrosis, and adipose infiltration (127).

Reliability and validity of US have been clearly documented in the renal setting for the assessment of quadriceps muscle thickness and CSA $(6-8,128)$. Specifically, the reliability of muscle US has been tested in critically ill patients with AKI, showing excellent intraclass correlation coefficients (ICC) for inter- and intra-operator comparisons (6). In the same clinical setting, US assessment of quadriceps muscle has also been validated against CT (8). Differential and proportional bias were small and not statistically significant, while the precision analysis showed slightly lower, though not clinically important, precision for muscle US in comparison to CT scan (8). US was also performed for the assessment of muscle CSA and was validated in CKD patients not on 
dialysis (128). In another reliability study, quadriceps muscle thickness values measured by US before and after RRT were not different, suggesting that US is poorly influenced by fluid overload and by rapid and relevant fluid shifts, such as those typical of patients on dialysis $(6,7)$. Despite such encouraging results, more work is needed before assuming muscle US as a reference method for the diagnosis of muscle wasting. Moreover, further studies aimed at defining cut-off values for muscle mass in the general population are needed, in order to allow the early identification of patients with low muscle mass.

\section{Conclusions}

Muscle wasting is highly prevalent among CKD/ESKD patients, and is associated with physical disability, worse quality of life and increased morbidity. In this regard, the assessment of nutritional status, and particularly of body composition, are mandatory for an adequate management of renal patients. The choice of the method will depend on its availability and ease of application in clinical practice, local experience, staff resources and good repeatability over time. Anthropometric measures can represent a valid surrogate of body composition parameters if standardized procedures are applied. BIA, another non-invasive and cheap method, despite its being easily performed at the bedside, also requires standard procedures to achieve reliable measurements and ensure their comparability and reproducibility over time, especially in CKD patients. Finally, muscle US, while representing a promising imaging technique as it is simple, easily applicable, valid, accurate and reliable, still needs that more data be accumulated before it can be recommended as a routine tool in clinical practice.

\section{Acknowledgments}

Funding: None.

\section{Footnote}

Provenance and Peer Review: With the arrangement by the Guest Editors and the editorial office, this article has been reviewed by external peers.

Conflicts of Interest: All authors have completed the ICMJE uniform disclosure form (available at http://dx.doi. org/10.21037/qims.2020.03.05). The special issue "Body Composition Imaging" was commissioned by the editorial office without any funding or sponsorship. GG served as the unpaid Guest Editor of the special issue and serves as an unpaid editorial board member of Quantitative Imaging in Medicine and Surgery. AB served as the unpaid Guest Editor of the special issue. The authors have no other conflicts of interest to declare.

Open Access Statement: This is an Open Access article distributed in accordance with the Creative Commons Attribution-NonCommercial-NoDerivs 4.0 International License (CC BY-NC-ND 4.0), which permits the noncommercial replication and distribution of the article with the strict proviso that no changes or edits are made and the original work is properly cited (including links to both the formal publication through the relevant DOI and the license). See: https://creativecommons.org/licenses/by-nc-nd/4.0/.

\section{References}

1. Hill NR, Fatoba ST, Oke JL, Hirst JA, O'Callaghan CA, Lasserson DS, Hobbs FD. Global Prevalence of Chronic Kidney Disease - A Systematic Review and Meta-Analysis. PLoS One 2016;11:e0158765.

2. Sabatino A, Regolisti G, Karupaiah T, Sahathevan S, Sadu Singh BK, Khor BH, Salhab N, Karavetian M, Cupisti A, Fiaccadori E. Protein-energy wasting and nutritional supplementation in patients with end-stage renal disease on hemodialysis. Clin Nutr 2017;36:663-71.

3. Marcelli D, Wabel P, Wieskotten S, Ciotola A, Grassmann A, Di Benedetto A, Canaud B. Physical methods for evaluating the nutrition status of hemodialysis patients. J Nephrol 2015;28:523-30.

4. Carrero JJ, Johansen KL, Lindholm B, Stenvinkel P, Cuppari L, Avesani CM. Screening for muscle wasting and dysfunction in patients with chronic kidney disease. Kidney Int 2016;90:53-66.

5. Rubbieri G, Mossello E, Di Bari M. Techniques for the diagnosis of sarcopenia. Clin Cases Miner Bone Metab 2014;11:181-4.

6. Sabatino A, Regolisti G, Bozzoli L, Fani F, Antoniotti R, Maggiore U, Fiaccadori E. Reliability of bedside ultrasound for measurement of quadriceps muscle thickness in critically ill patients with acute kidney injury. Clin Nutr 2017;36:1710-5.

7. Sabatino A, Regolisti G, Delsante M, Di Motta T, Cantarelli C, Pioli S, Grassi G, Batini V, Gregorini M, Fiaccadori E. Noninvasive evaluation of muscle mass by ultrasonography of quadriceps femoris muscle in End- 
Stage Renal Disease patients on hemodialysis. Clin Nutr 2019;38:1232-9.

8. Sabatino A, Regolisti G, di Mario F, Ciuni A, Palumbo A, Peyronel F, Maggiore U, Fiaccadori E. Validation by CT scan of quadriceps muscle ultrasound in acute kidney injury. J Nephrol 2020;33:109-17.

9. Greening NJ, Harvey-Dunstan TC, Chaplin EJ, Vincent EE, Morgan MD, Singh SJ, Steiner MC. Bedside assessment of quadriceps muscle by ultrasound after admission for acute exacerbations of chronic respiratory disease. Am J Respir Crit Care Med 2015;192:810-6.

10. Thomaes T, Thomis M, Onkelinx S, Coudyzer W, Cornelissen V, Vanhees L. Reliability and validity of the ultrasound technique to measure the rectus femoris muscle diameter in older CAD-patients. BMC Med Imaging 2012;12:7.

11. Puthucheary ZA, Phadke R, Rawal J, McPhail MJ, Sidhu PS, Rowlerson A, Moxham J, Harridge S, Hart N, Montgomery HE. Qualitative Ultrasound in Acute Critical Illness Muscle Wasting. Crit Care Med 2015;43:1603-11.

12. Mourtzakis M, Wischmeyer P. Bedside ultrasound measurement of skeletal muscle. Curr Opin Clin Nutr Metab Care 2014;17:389-95.

13. Segers J, Hermans G, Charususin N, Fivez T, Vanhorebeek I, Van den Berghe G, Gosselink R. Assessment of quadriceps muscle mass with ultrasound in critically ill patients: intra- and inter-observer agreement and sensitivity. Intensive Care Med 2015;41:562-3.

14. Seymour JM, Ward K, Sidhu PS, Puthucheary Z, Steier J, Jolley CJ, Rafferty G, Polkey MI, Moxham J. Ultrasound measurement of rectus femoris cross-sectional area and the relationship with quadriceps strength in COPD. Thorax 2009;64:418-23.

15. Shiozu H, Higashijima M, Koga T. Association of sarcopenia with swallowing problems, related to nutrition and activities of daily living of elderly individuals. J Phys Ther Sci 2015;27:393-6.

16. Argilés JM, Campos N, Lopez-Pedrosa JM, Rueda R, Rodriguez-Manas L. Skeletal Muscle Regulates Metabolism via Interorgan Crosstalk: Roles in Health and Disease. J Am Med Dir Assoc 2016;17:789-96.

17. Wolfe RR. The underappreciated role of muscle in health and disease. Am J Clin Nutr 2006;84:475-82.

18. Demling RH. Nutrition, anabolism, and the wound healing process: an overview. Eplasty 2009;9:e9.

19. Landi F, Camprubi-Robles M, Bear DE, Cederholm T,
Malafarina V, Welch AA, Cruz-Jentoft AJ. Muscle loss: The new malnutrition challenge in clinical practice. Clin Nutr 2019;38:2113-20.

20. Domański M, Ciechanowski K. Sarcopenia: a major challenge in elderly patients with end-stage renal disease. J Aging Res 2012;2012:754739.

21. Ozkayar N, Altun B, Halil M, Kuyumcu ME, Arik G, Yesil Y, Yildirim T, Yilmaz R, Ariogul S, Turgan C. Evaluation of sarcopenia in renal transplant recipients. Nephrourol Mon 2014;6:e20055.

22. Kim HY. Nutritional intervention for a patient with diabetic nephropathy. Clin Nutr Res 2014;3:64-8.

23. Thompson DD. Aging and sarcopenia. J Musculoskelet Neuronal Interact 2007;7:344-5.

24. Foley RN, Wang C, Ishani A, Collins AJ, Murray AM. Kidney function and sarcopenia in the United States general population: NHANES III. Am J Nephrol 2007;27:279-86.

25. Carrero JJ, Chmielewski M, Axelsson J, Snaedal S, Heimburger O, Barany P, Suliman ME, Lindholm B, Stenvinkel P, Qureshi AR. Muscle atrophy, inflammation and clinical outcome in incident and prevalent dialysis patients. Clin Nutr 2008;27:557-64.

26. Miyamoto T, Carrero JJ, Qureshi AR, Anderstam B, Heimburger O, Barany P, Lindholm B, Stenvinkel P. Circulating follistatin in patients with chronic kidney disease: implications for muscle strength, bone mineral density, inflammation, and survival. Clin J Am Soc Nephrol 2011;6:1001-8.

27. Martinson M, Ikizler TA, Morrell G, Wei G, Almeida N, Marcus RL, Filipowicz R, Greene TH, Beddhu S. Associations of body size and body composition with functional ability and quality of life in hemodialysis patients. Clin J Am Soc Nephrol 2014;9:1082-90.

28. Beddhu S, Pappas LM, Ramkumar N, Samore M. Effects of body size and body composition on survival in hemodialysis patients. J Am Soc Nephrol 2003;14:2366-72.

29. Noori N, Kopple JD, Kovesdy CP, Feroze U, Sim JJ, Murali SB, Luna A, Gomez M, Luna C, Bross R, Nissenson AR, Kalantar-Zadeh K. Mid-arm muscle circumference and quality of life and survival in maintenance hemodialysis patients. Clin J Am Soc Nephrol 2010;5:2258-68.

30. Streja E, Molnar MZ, Kovesdy CP, Bunnapradist S, Jing J, Nissenson AR, Mucsi I, Danovitch GM, Kalantar-Zadeh K. Associations of pretransplant weight and muscle mass with mortality in renal transplant recipients. Clin J Am Soc Nephrol 2011;6:1463-73. 
31. Englesbe MJ, Patel SP, He K, Lynch RJ, Schaubel DE, Harbaugh C, Holcombe SA, Wang SC, Segev DL, Sonnenday CJ. Sarcopenia and mortality after liver transplantation. J Am Coll Surg 2010;211:271-8.

32. Oterdoom LH, van Ree RM, de Vries AP, Gansevoort RT, Schouten JP, van Son WJ, Homan van der Heide JJ, Navis G, de Jong PE, Gans RO, Bakker SJ. Urinary creatinine excretion reflecting muscle mass is a predictor of mortality and graft loss in renal transplant recipients. Transplantation 2008;86:391-8.

33. Barone M, Viggiani MT, Avolio AW, Iannone A, Rendina M, Di Leo A. Obesity as predictor of postoperative outcomes in liver transplant candidates: Review of the literature and future perspectives. Dig Liver Dis 2017;49:957-66.

34. Coats AJ. Origin of symptoms in patients with cachexia with special reference to weakness and shortness of breath. Int J Cardiol 2002;85:133-9.

35. Workeneh BT, Mitch WE. Review of muscle wasting associated with chronic kidney disease. Am J Clin Nutr 2010;91:1128S-32S.

36. Marquis K, Debigare R, Lacasse Y, LeBlanc P, Jobin J, Carrier G, Maltais F. Midthigh muscle cross-sectional area is a better predictor of mortality than body mass index in patients with chronic obstructive pulmonary disease. Am J Respir Crit Care Med 2002;166:809-13.

37. Swallow EB, Reyes D, Hopkinson NS, Man WD, Porcher R, Cetti EJ, Moore AJ, Moxham J, Polkey MI. Quadriceps strength predicts mortality in patients with moderate to severe chronic obstructive pulmonary disease. Thorax 2007;62:115-20.

38. Vestbo J, Prescott E, Almdal T, Dahl M, Nordestgaard BG, Andersen T, Sorensen TI, Lange P. Body mass, fatfree body mass, and prognosis in patients with chronic obstructive pulmonary disease from a random population sample: findings from the Copenhagen City Heart Study. Am J Respir Crit Care Med 2006;173:79-83.

39. Doucet M, Dube A, Joanisse DR, Debigare R, Michaud A, Pare ME, Vaillancourt R, Frechette E, Maltais F. Atrophy and hypertrophy signalling of the quadriceps and diaphragm in COPD. Thorax 2010;65:963-70.

40. Testelmans D, Crul T, Maes K, Agten A, Crombach M, Decramer M, Gayan-Ramirez G. Atrophy and hypertrophy signalling in the diaphragm of patients with COPD. Eur Respir J 2010;35:549-56.

41. Sandri M, Sandri C, Gilbert A, Skurk C, Calabria E, Picard A, Walsh K, Schiaffino S, Lecker SH, Goldberg AL. Foxo transcription factors induce the atrophy-related ubiquitin ligase atrogin-1 and cause skeletal muscle atrophy. Cell 2004;117:399-412.

42. Crul T, Testelmans D, Spruit MA, Troosters T, Gosselink R, Geeraerts I, Decramer M, Gayan-Ramirez G. Gene expression profiling in vastus lateralis muscle during an acute exacerbation of COPD. Cell Physiol Biochem 2010;25:491-500.

43. Cohen S, Nathan JA, Goldberg AL. Muscle wasting in disease: molecular mechanisms and promising therapies. Nat Rev Drug Discov 2015;14:58-74.

44. Cruz-Jentoft AJ, Baeyens JP, Bauer JM, Boirie Y, Cederholm T, Landi F, Martin FC, Michel JP, Rolland Y, Schneider SM, Topinkova E, Vandewoude M, Zamboni M. Sarcopenia: European consensus on definition and diagnosis: Report of the European Working Group on Sarcopenia in Older People. Age Ageing 2010;39:412-23.

45. Raj DS, Sun Y, Tzamaloukas AH. Hypercatabolism in dialysis patients. Curr Opin Nephrol Hypertens 2008;17:589-94.

46. Honda H, Qureshi AR, Axelsson J, Heimburger O, Suliman ME, Barany P, Stenvinkel P, Lindholm B. Obese sarcopenia in patients with end-stage renal disease is associated with inflammation and increased mortality. Am J Clin Nutr 2007;86:633-8.

47. Bossola M, Tazza L, Giungi S, Luciani G. Anorexia in hemodialysis patients: an update. Kidney Int 2006;70:417-22.

48. Hahn D, Hodson EM, Fouque D. Low protein diets for non-diabetic adults with chronic kidney disease. Cochrane Database Syst Rev 2018;10:CD001892.

49. Kovesdy CP, Kopple JD, Kalantar-Zadeh K. Management of protein-energy wasting in non-dialysisdependent chronic kidney disease: reconciling low protein intake with nutritional therapy. Am J Clin Nutr 2013;97:1163-77.

50. Ikizler TA, Cano NJ, Franch H, Fouque D, Himmelfarb J, Kalantar-Zadeh K, Kuhlmann MK, Stenvinkel P, TerWee P, Teta D, Wang AY, Wanner C, Metabolism ISoRNa. Prevention and treatment of protein energy wasting in chronic kidney disease patients: a consensus statement by the International Society of Renal Nutrition and Metabolism. Kidney Int 2013;84:1096-107.

51. Obi Y, Qader H, Kovesdy CP, Kalantar-Zadeh K. Latest consensus and update on protein-energy wasting in chronic kidney disease. Curr Opin Clin Nutr Metab Care 2015;18:254-62.

52. Wang XH, Mitch WE. Mechanisms of muscle 
wasting in chronic kidney disease. Nat Rev Nephrol 2014;10:504-16.

53. Kraut JA, Madias NE. Lactic Acidosis: Current Treatments and Future Directions. Am J Kidney Dis 2016;68:473-82.

54. Abramowitz MK, Hostetter TH, Melamed ML. Association of serum bicarbonate levels with gait speed and quadriceps strength in older adults. Am J Kidney Dis 2011;58:29-38.

55. Kraut JA, Madias NE. Consequences and therapy of the metabolic acidosis of chronic kidney disease. Pediatr Nephrol 2011;26:19-28.

56. Siew ED, Ikizler TA. Insulin resistance and protein energy metabolism in patients with advanced chronic kidney disease. Semin Dial 2010;23:378-82.

57. Garibotto G, Sofia A, Russo R, Paoletti E, Bonanni A, Parodi EL, Viazzi F, Verzola D. Insulin sensitivity of muscle protein metabolism is altered in patients with chronic kidney disease and metabolic acidosis. Kidney Int 2015;88:1419-26.

58. Dobre M, Rahman M, Hostetter TH. Current status of bicarbonate in CKD. J Am Soc Nephrol 2015;26:515-23.

59. Pupim LB, Heimburger O, Qureshi AR, Ikizler TA, Stenvinkel P. Accelerated lean body mass loss in incident chronic dialysis patients with diabetes mellitus. Kidney Int 2005;68:2368-74.

60. Pupim LB, Flakoll PJ, Majchrzak KM, Aftab Guy DL, Stenvinkel P, Ikizler TA. Increased muscle protein breakdown in chronic hemodialysis patients with type 2 diabetes mellitus. Kidney Int 2005;68:1857-65.

61. Siew ED, Pupim LB, Majchrzak KM, Shintani A, Flakoll PJ, Ikizler TA. Insulin resistance is associated with skeletal muscle protein breakdown in non-diabetic chronic hemodialysis patients. Kidney Int 2007;71:146-52.

62. Remuzzi A. Vitamin D, insulin resistance, and renal disease. Kidney Int 2007;71:96-8.

63. Norman AW, Frankel JB, Heldt AM, Grodsky GM. Vitamin D deficiency inhibits pancreatic secretion of insulin. Science 1980;209:823-5.

64. Bischoff Ferrari HA. Validated treatments and therapeutic perspectives regarding nutritherapy. J Nutr Health Aging 2009;13:737-41

65. Pupim LB, Ikizler TA. Uremic malnutrition: new insights into an old problem. Semin Dial 2003;16:224-32.

66. Ramezani A, Raj DS. The gut microbiome, kidney disease, and targeted interventions. J Am Soc Nephrol 2014;25:657-70.

67. Mafra D, Fouque D. Gut microbiota and inflammation in chronic kidney disease patients. Clin Kidney J
2015;8:332-4.

68. Sabatino A, Regolisti G, Brusasco I, Cabassi A, Morabito $\mathrm{S}$, Fiaccadori E. Alterations of intestinal barrier and microbiota in chronic kidney disease. Nephrol Dial Transplant 2015;30:924-33.

69. Ramezani A, Massy ZA, Meijers B, Evenepoel P, Vanholder R, Raj DS. Role of the Gut Microbiome in Uremia: A Potential Therapeutic Target. Am J Kidney Dis 2016;67:483-98.

70. Cosola C, Rocchetti MT, Sabatino A, Fiaccadori E, Di Iorio BR, Gesualdo L. Microbiota issue in CKD: how promising are gut-targeted approaches? J Nephrol 2019;32:27-37.

71. Fiaccadori E, Sabatino A, Morabito S, Bozzoli L, Donadio C, Maggiore U, Regolisti G. Hyper/hypoglycemia and acute kidney injury in critically ill patients. Clin Nutr 2016;35:317-21.

72. Fiaccadori E, Cosola C, Sabatino A. Targeting the Gut for Early Diagnosis, Prevention, and Cure of Diabetic Kidney Disease: Is the Phenyl Sulfate Story Another Step Forward? Am J Kidney Dis 2020;75:144-7.

73. Heiwe S, Jacobson SH. Exercise training for adults with chronic kidney disease. Cochrane Database Syst Rev 2011;(10):CD003236.

74. Johansen KL, Chertow GM, Kutner NG, Dalrymple LS, Grimes BA, Kaysen GA. Low level of self-reported physical activity in ambulatory patients new to dialysis. Kidney Int 2010;78:1164-70.

75. Regolisti G, Maggiore U, Sabatino A, Gandolfini I, Pioli S, Torino C, Aucella F, Cupisti A, Pistolesi V, Capitanini A, Caloro G, Gregorini M, Battaglia Y, Mandreoli M, Dani L, Mosconi G, Bellizzi V, Di Iorio BR, Conti P, Fiaccadori E. Interaction of healthcare staff's attitude with barriers to physical activity in hemodialysis patients: A quantitative assessment. PLoS One 2018;13:e0196313.

76. Fiaccadori E, Sabatino A, Schito F, Angella F, Malagoli M, Tucci M, Cupisti A, Capitanini A, Regolisti G. Barriers to physical activity in chronic hemodialysis patients: a singlecenter pilot study in an Italian dialysis facility. Kidney Blood Press Res 2014;39:169-75.

77. Aucella F, Battaglia Y, Bellizzi V, Bolignano D, Capitanini A, Cupisti A. Physical exercise programs in CKD: lights, shades and perspectives [corrected]. J Nephrol 2015;28:143-50.

78. Utkualp N, Ercan I. Anthropometric Measurements Usage in Medical Sciences. Biomed Res Int 2015;2015:404261.

79. Dwyer JT, Larive B, Leung J, Rocco MV, Greene T, 
Burrowes J, Chertow GM, Cockram DB, Chumlea WC, Daugirdas J, Frydrych A, Kusek JW. Are nutritional status indicators associated with mortality in the Hemodialysis (HEMO) Study? Kidney Int 2005;68:1766-76.

80. Bauer J, Morley JE, Schols A, Ferrucci L, Cruz-Jentoft AJ, Dent E, Baracos VE, Crawford JA, Doehner W, Heymsfield SB, Jatoi A, Kalantar-Zadeh K, Lainscak M, Landi F, Laviano A, Mancuso M, Muscaritoli M, Prado CM, Strasser F, von Haehling S, Coats AJS, Anker SD. Sarcopenia: A Time for Action. An SCWD Position Paper. J Cachexia Sarcopenia Muscle 2019;10:956-61.

81. Chumlea WC, Guo S, Roche AF, Steinbaugh ML. Prediction of body weight for the nonambulatory elderly from anthropometry. J Am Diet Assoc 1988;88:564-8.

82. Jackson AS, Pollock ML. Generalized equations for predicting body density of men. 1978. Br J Nutr 2004;91:161-8.

83. Kalantar-Zadeh K, Kuwae N, Wu DY, Shantouf RS, Fouque D, Anker SD, Block G, Kopple JD. Associations of body fat and its changes over time with quality of life and prospective mortality in hemodialysis patients. Am J Clin Nutr 2006;83:202-10.

84. Araújo IC, Kamimura MA, Draibe SA, Canziani ME, Manfredi SR, Avesani CM, Sesso R, Cuppari L. Nutritional parameters and mortality in incident hemodialysis patients. J Ren Nutr 2006;16:27-35.

85. Cano NJ, Miolane-Debouit M, Leger J, Heng AE. Assessment of body protein: energy status in chronic kidney disease. Semin Nephrol 2009;29:59-66.

86. Grundmann O, Yoon SL, Williams JJ. The value of bioelectrical impedance analysis and phase angle in the evaluation of malnutrition and quality of life in cancer patients--a comprehensive review. Eur J Clin Nutr 2015;69:1290-7.

87. Małecka-Massalska T, Mlak R, Smolen A, Morshed $\mathrm{K}$. Bioelectrical impedance phase angle and subjective global assessment in detecting malnutrition among newly diagnosed head and neck cancer patients. Eur Arch Otorhinolaryngol 2016;273:1299-305.

88. Lee JY, Kim JS, Yang JW, Choi SO, Sohn JH, Han BG. Serum leptin level is associated with phase angle in CKD5 patients not undergoing dialysis. PLoS One 2018;13:e0202055.

89. Caravaca F, Martinez del Viejo C, Villa J, Martinez Gallardo R, Ferreira F. Hydration status assessment by multi-frequency bioimpedance in patients with advanced chronic kidney disease. Nefrologia 2011;31:537-44.

90. Sarmento-Dias M, Santos-Araujo C, Poinhos R, Oliveira
B, Sousa M, Simoes-Silva L, Soares-Silva I, Correia F, Pestana M. Phase Angle Predicts Arterial Stiffness and Vascular Calcification in Peritoneal Dialysis Patients. Perit Dial Int 2017;37:451-7.

91. Shin JH, Kim CR, Park KH, Hwang JH, Kim SH. Predicting clinical outcomes using phase angle as assessed by bioelectrical impedance analysis in maintenance hemodialysis patients. Nutrition 2017;41:7-13.

92. Beberashvili I, Azar A, Sinuani I, Shapiro G, Feldman L, Stav K, Sandbank J, Averbukh Z. Bioimpedance phase angle predicts muscle function, quality of life and clinical outcome in maintenance hemodialysis patients. Eur J Clin Nutr 2014;68:683-9.

93. Han BG, Lee JY, Kim JS, Yang JW. Clinical Significance of Phase Angle in Non-Dialysis CKD Stage 5 and Peritoneal Dialysis Patients. Nutrients 2018. doi: 10.3390/ nu10091331.

94. Piccoli A. Identification of operational clues to dry weight prescription in hemodialysis using bioimpedance vector analysis. The Italian Hemodialysis-Bioelectrical Impedance Analysis (HD-BIA) Study Group. Kidney Int 1998;53:1036-43.

95. Naranjo-Hernandéz D, Reina-Tosina J, Min M. Fundamentals, Recent Advances, and Future Challenges in Bioimpedance Devices for Healthcare Applications. Journal of Sensors 2019:1-42.

96. Mulasi U, Kuchnia AJ, Cole AJ, Earthman CP. Bioimpedance at the bedside: current applications, limitations, and opportunities. Nutr Clin Pract 2015;30:180-93.

97. Piccoli A, Rossi B, Pillon L, Bucciante G. A new method for monitoring body fluid variation by bioimpedance analysis: the RXc graph. Kidney Int 1994;46:534-9.

98. Kaysen GA, Zhu F, Sarkar S, Heymsfield SB, Wong J, Kaitwatcharachai C, Kuhlmann MK, Levin NW. Estimation of total-body and limb muscle mass in hemodialysis patients by using multifrequency bioimpedance spectroscopy. Am J Clin Nutr 2005;82:988-95.

99. Carter M, Zhu F, Kotanko P, Kuhlmann M, Ramirez L, Heymsfield SB, Handelman G, Levin NW. Assessment of body composition in dialysis patients by arm bioimpedance compared to MRI and $40 \mathrm{~K}$ measurements. Blood Purif 2009;27:330-7.

100. Di Iorio BR, Scalfi L, Terracciano V, Bellizzi V. A systematic evaluation of bioelectrical impedance measurement after hemodialysis session. Kidney Int 2004;65:2435-40. 
101.Parmentier SP, Schirutschke H, Schmitt B, Schewe J, Herbrig K, Pistrosch F, Passauer J. Influence of peritoneal dialysis solution on measurements of fluid status by bioimpedance spectroscopy. Int Urol Nephrol 2013;45:229-32.

102. Davenport A. Does peritoneal dialysate affect body composition assessments using multi-frequency bioimpedance in peritoneal dialysis patients? Eur J Clin Nutr 2013;67:223-5.

103.Pietrobelli A, Formica C, Wang Z, Heymsfield SB. Dual-energy X-ray absorptiometry body composition model: review of physical concepts. Am J Physiol 1996;271:E941-51.

104. Fukasawa H, Kaneko M, Niwa H, Matsuyama T, Yasuda H, Kumagai H, Furuya R. Lower Thigh Muscle Mass Is Associated With All-Cause and Cardiovascular Mortality in Elderly Hemodialysis Patients. Eur J Clin Nutr 2017;71:64-9.

105. Ohkawa S, Odamaki M, Yoneyama T, Hibi I, Miyaji K, Kumagai H. Standardized Thigh Muscle Area Measured by Computed Axial Tomography as an Alternate Muscle Mass Index for Nutritional Assessment of Hemodialysis Patients. Am J Clin Nutr 2000;71:485-90.

106. Cawthon PM. Assessment of Lean Mass and Physical Performance in Sarcopenia. J Clin Densitom 2015;18:467-71.

107. Braunschweig CA, Sheean PM, Peterson SJ, Gomez Perez S, Freels S, Troy KL, Ajanaku FC, Patel A, Sclamberg JS, Wang Z. Exploitation of diagnostic computed tomography scans to assess the impact of nutrition support on body composition changes in respiratory failure patients. JPEN J Parenter Enteral Nutr 2014;38:880-5.

108. Cruz-Jentoft AJ, Bahat G, Bauer J, Boirie Y, Bruyere O, Cederholm T, Cooper C, Landi F, Rolland Y, Sayer AA, Schneider SM, Sieber CC, Topinkova E, Vandewoude M, Visser M, Zamboni M. Sarcopenia: revised European consensus on definition and diagnosis. Age Ageing 2019;48:16-31.

109. Fukushima H, Koga F. Impact of sarcopenia in the management of urological cancer patients. Expert Rev Anticancer Ther 2017;17:455-66.

110. Shen W, Punyanitya M, Wang Z, Gallagher D, St-Onge M, Albu J, Heymsfield S, Heshka S. Total Body Skeletal Muscle and Adipose Tissue Volumes: Estimation From a Single Abdominal Cross-Sectional Image. J Appl Physiol (1985) 2004;97:2333-8.

111. Mourtzakis M, Prado C, Lieffers J, Reiman T, McCargar L, Baracos V. A Practical and Precise Approach to
Quantification of Body Composition in Cancer Patients Using Computed Tomography Images Acquired During Routine Care. Appl Physiol Nutr Metab 2008;33:997-1006. 112. Giglio J, Kamimura M, Souza N, Bichels A, Cordeiro A, Pinho N, Avesani C. Muscle Mass Assessment by Computed Tomography in Chronic Kidney Disease Patients: Agreement With Surrogate Methods. Eur J Clin Nutr 2019;73:46-53.

113. Borga M, West J, Bell J, Harvey N, Romu T, Heymsfield S, Dahlqvist Leinhard O. Advanced Body Composition Assessment: From Body Mass Index to Body Composition Profiling. J Investig Med 2018;66:1-9.

114. Dixon WT. Simple Proton Spectroscopic Imaging.

Radiology 1984;153:189-94.

115. West J, Romu T, Thorell S, Lindblom H, Berin E, Holm A, Åstrand L, Karlsson A, Borga M, Hammar M, Leinhard O. Precision of MRI-based Body Composition Measurements of Postmenopausal Women. PLoS One 2018;13:e0192495.

116. Wald D, Teucher B, Dinkel J, Kaaks R, Delorme S, Boeing H, Seidensaal K, Meinzer H, Heimann T. Automatic Quantification of Subcutaneous and Visceral Adipose Tissue From Whole-Body Magnetic Resonance Images Suitable for Large Cohort Studies. J Magn Reson Imaging 2012;36:1421-34.

117. Brennan DD, Whelan P, Robinson K, Ghita O, O'Brien J, Sadleir R, Eustace S. Rapid Automated Measurement of Body Fat Distribution From Whole-Body MRI. AJR Am J Roentgenol 2005;185:418-23.

118. Karlsson A, Rosander J, Romu T, Tallberg J, Grönqvist A, Borga M, Dahlqvist Leinhard O. Automatic and Quantitative Assessment of Regional Muscle Volume by Multi-Atlas Segmentation Using Whole-Body Water-Fat MRI. J Magn Reson Imaging 2015;41:1558-69.

119. Thomas MS, Newman D, Leinhard O, Kasmai B, Greenwood R, Malcolm P, Karlsson A, Rosander J, Borga M, Toms A. Test-retest Reliability of Automated Whole Body and Compartmental Muscle Volume Measurements on a Wide Bore 3T MR System. Eur Radiol 2014;24:2279-91.

120. Brunner G, Nambi V, Yang E, Kumar A, Virani S, Kougias P, Shah D, Lumsden A, Ballantyne C, Morrisett J. Automatic Quantification of Muscle Volumes in Magnetic Resonance Imaging Scans of the Lower Extremities. Magn Reson Imaging 2011;29:1065-75.

121.Peterson P, Romu T, Brorson H, Dahlqvist Leinhard O, Månsson S. Fat Quantification in Skeletal Muscle Using Multigradient-Echo Imaging: Comparison of Fat and Water 
References. J Magn Reson Imaging 2016;43:203-12.

122. Delgado C, Doyle J, Johansen K. Association of Frailty With Body Composition Among Patients on Hemodialysis. J Ren Nutr 2013;23:356-62.

123. Morrell GR, Ikizler T, Chen X, Heilbrun M, Wei G, Boucher R, Beddhu S. Psoas Muscle Cross-sectional Area as a Measure of Whole-body Lean Muscle Mass in Maintenance Hemodialysis Patients. J Ren Nutr 2016;26:258-64.

124. Reeves ND, Maganaris CN, Narici MV. Ultrasonographic assessment of human skeletal muscle size. Eur J Appl Physiol 2004;91:116-8.

125.Al-Gindan YY, Hankey CR, Leslie W, Govan L, Lean ME. Predicting muscle mass from anthropometry using magnetic resonance imaging as reference: a systematic

Cite this article as: Sabatino A, D'Alessandro C, Regolisti G, di Mario F, Guglielmi G, Bazzocchi A, Fiaccadori E. Muscle mass assessment in renal disease: the role of imaging techniques. Quant Imaging Med Surg 2020;10(8):1672-1686. doi: 10.21037/ qims.2020.03.05 review. Nutr Rev 2014;72:113-26.

126. Connolly B, MacBean V, Crowley C, Lunt A, Moxham J, Rafferty GF, Hart N. Ultrasound for the assessment of peripheral skeletal muscle architecture in critical illness: a systematic review. Crit Care Med 2015;43:897-905.

127. Ticinesi A, Meschi T, Narici MV, Lauretani F, Maggio M. Muscle Ultrasound and Sarcopenia in Older Individuals: A Clinical Perspective. J Am Med Dir Assoc 2017;18:290-300.

128. Souza VA, Oliveira D, Cupolilo EN, Miranda CS, Colugnati FAB, Mansur HN, Fernandes N, Bastos MG. Rectus femoris muscle mass evaluation by ultrasound: facilitating sarcopenia diagnosis in pre-dialysis chronic kidney disease stages. Clinics (Sao Paulo) 2018;73:e392. 